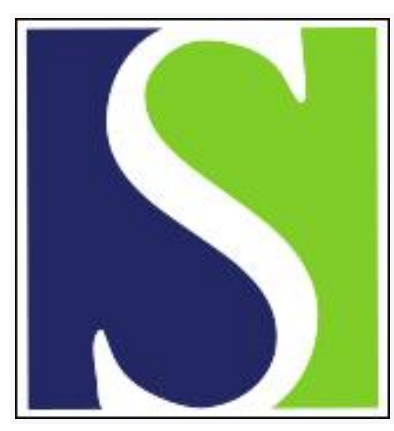

Scand J Work Environ Health 1995;21(6):517-520

https://doi.org/10.5271/sjweh.69

Issue date: Dec 1995

\title{
Peripheral neuropathy in styrene-exposed workers
}

by Gobba F, Cavalleri F, Bontadi D, Torri P, Dainese R

Key terms: biological monitoring; color-vision loss; exposure limit; occupational exposure; peripheral neuropathy; styrene

This article in PubMed: www.ncbi.nlm.nih.gov/pubmed/8824759

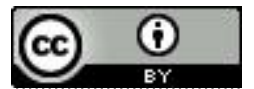




\title{
Peripheral neuropathy in styrene-exposed workers
}

\author{
by Fabriziomaria Gobba, MD, ${ }^{1}$ Francesca Cavalleri, MD, ${ }^{2}$ Danilo Bontadi, MD, ${ }^{3}$ Paola Torri, $M D,{ }^{3}$ \\ Rinaldo Dainese, $M D^{4}$
}

\begin{abstract}
Gobba F, Cavalleri F, Bontadi D, Torri P, Dainese R. Peripheral neuropathy in styrene-exposed workers. Scand J Work Environ Health 1995;21:517-20.

Background The toxicity of styrene on the peripheral nervous system is still debated.

Cases The paper presents two cases of peripheral sensorimotor neuropathy in styrene-exposed workers. Exposure, evaluated by biological monitoring, ranged between 100 and $150 \%$ of the current limits proposed by the American Conference of Governmental Industrial Hygienists (ACGIH). The subjects complained of leg weakness and numbness, cramps, and paresthesia. Electrophysiology revealed a moderate peripheral sensorimotor neuropathy of a demyelinating type. Color-vision testing showed a subclinical deficit. Common inherited and acquired causes of peripheral neuropathy and dyschromatopsia other than styrene were ruled out by personal history, medical examination, laboratory data, and chest X-ray.

Conclusions The results suggest that long-term occupational exposure to environmental levels of styrene that are equal, or slightly above, the ACGIH limits can induce a clinical form of peripheral neuropathy and a subclinical impairment of color vision. As a consequence, a careful reappraisal of the real preventive meaning of the current ACGIH occupational limit for styrene, at least on an individual basis, is needed.
\end{abstract}

Key terms biological monitoring, color-vision loss, exposure limits, occupational exposure, peripheral neuropathy, styrene.

Occupational exposure to styrene can affect the central nervous system (1). According to some authors (2-4), this effect can occur at environmental levels of the solvent that are lower than $50 \mathrm{ppm}\left(213 \mathrm{mg} \cdot \mathrm{m}^{-3}\right)$, the current threshold limit value time-weighted average (TLV-TWA) proposed by the American Conference of Governmental Industrial Hygienists (ACGIH) (5).

The effects of styrene on the peripheral nervous system are still debated. Electrophysiological results $(6-8)$ and histopathological findings (8) not only support the hypothesis of peripheral neuropathy in heavily exposed workers, but also in subjects exposed to environmental levels lower than $50 \mathrm{ppm}$. Faster myelinated fibers of peripheral sensory nerves can be affected (9). Other studies failed to observe any involvement of the peripheral nervous system in occupational styrene exposure (10). Recently, an early impairment of color vision was observed in workers exposed to environmental levels of styrene lower than $50 \mathrm{ppm}$ (11). This effect seems to reflect solvent-induced functional changes in the optical pathways and may be detectable before overt symptoms or other visual abnormalities.

We present two cases of peripheral sensorimotor neuropathy and subclinical color-vision loss in workers exposed to styrene levels near the current ACGIH limit.

\section{Case reports}

Case 1. CC, a 38-year-old man, had an unremarkable family and personal history. He was not taking medication and was not at risk of HIV (human immunodeficiency virus) infection. He had smoked 20 cigarettes a day for the last 18 years. His alcohol intake did not exceed 23 $\mathrm{g}$ of pure ethanol per day. There was no history of drug abuse. He was exposed to styrene in the production of fiber-glass reinforced plastic products from 1981 to 1985 as a spray laminator and from 1986 to 1992 as a hand laminator. The results of biological monitoring performed in 1991 and 1992 are reported in table 1.

In 1991, at the end of a period of increased production of fiber-glass reinforced products, he noted weak-

1 Chair of Occupational Medicine, Department of Biomedical Sciences, University of Modena, Modena, Italy.

2 Department of Neurology, University of Modena, Modena, Italy.

3 Studio GOMI, Padova, Italy.

4 Department of Neurophysiopathology, Rovigo Civil Hospital, ULSS of Rovigo, Rovigo, Italy.

Reprints requests to: Dr F Gobba, Chair of Occupational Medicine, Department of Biomedical Sciences, University of Modena, Via Campi 287, 41100 Modena (MO), Italy. 
ness, tingling, and numbness of the legs. He also complained of occasional calf muscle cramps. A general physical examination did not reveal any abnormal finding. A neurological examination showed only diminished reflexes of the lower limbs. His mental status was intact. Plasma glucose, serum alanine aminotransferase (ALT), serum aspartate aminotransferase (AST), gamma-glutamyltranspeptidase ( $/ \mathrm{GT}$ ), alkaline phosphatase (ALP), bilirubin, creatinine, electrolytes, protein electrophoresis, and urine analysis were within their normal range, as well as serum vitamin B12 and pholates. Infectious and neoplastic diseases were ruled out by personal history, laboratory data, and chest radiography. Electrophysiology revealed a moderate sensorimotor neuropathy of a demyelinating type. The right peroneal nerve had a slightly reduced motor conduction velocity (MCV) $\left(46 \mathrm{~m} \cdot \mathrm{s}^{-1}\right)$ and increased distal and proximal latency (DL, PL) (6 and $16 \mathrm{~ms}$, respectively). The motor action potential (MAP) was polyphasic, but its amplitude was in the normal range. The right sural and median nerves had reduced sensory conduction velocity (SCV) (40 and $37 \mathrm{~m} \cdot \mathrm{s}^{-1}$, respectively) and diminished sensory action potential (SAP) amplitude (4 and $6 \mu \mathrm{V}$, respectively). Conduction blocks were excluded. Denervation signs were absent in the electromyographic (EMG) examination. Color vision was evaluated with the Lanthony D-15 desaturated test (D-15 d); the method has been described elsewhere (11). The color confusion index (CCI) - mean of the two eyes - was 1.34. (The 10th and 90th percentiles of the CCI values determined for a group of 63 unexposed subjects, aged 30 and 39 years, were $1.00-$ 1.28, respectively). During 1991 his styrene exposure remained substantially unchanged. A new electrophysiological examination, performed one year later, confirmed the demyelinating sensorimotor neuropathy; his peroneal MCV was further reduced $\left(41 \mathrm{~m} \cdot \mathrm{s}^{-1}\right)$ compared with the previous examination, but its MAP was still normal in amplitude. The homolateral ulnar nerve had a moderately diminished MCV $\left(49 \mathrm{~m} \cdot \mathrm{s}^{-1}\right)$ and an increased SAP DL $(6 \mathrm{~ms})$. His color-vision loss was slightly increased $(\mathrm{CCI}=1.57)$.

Table 1. Results of the biological monitoring of the two styreneexposed workers.

\begin{tabular}{|c|c|c|c|c|}
\hline \multirow[t]{2}{*}{ Subject } & \multicolumn{2}{|c|}{1991} & \multicolumn{2}{|c|}{1992} \\
\hline & $\begin{array}{c}\text { Urinary } \\
\text { styrenea } \\
\left(\left.\mathrm{mg} \cdot\right|^{-1}\right)\end{array}$ & $\begin{array}{l}\text { Urinary } \\
\text { mandelic } \\
\text { acidb } \\
\text { (mg } \cdot g \\
\text { creatinine } \\
\text { c-1) }\end{array}$ & $\begin{array}{l}\text { Urinary } \\
\text { styrene }^{a} \\
\left(\left.\mathrm{mg} \cdot\right|^{-1}\right)\end{array}$ & $\begin{array}{c}\text { Urinary } \\
\text { mandelic } \\
\text { acid } \\
\text { (mig } \cdot g \\
\left.\text { creatinine }{ }^{-1}\right)\end{array}$ \\
\hline $\begin{array}{l}\mathrm{CC} \\
\mathrm{PL}\end{array}$ & $\begin{array}{r}78.8 \\
126.5\end{array}$ & $\begin{array}{l}940 \\
960\end{array}$ & $10 \ddot{7.4}$ & $\begin{array}{r}763 \\
1001\end{array}$ \\
\hline
\end{tabular}

a Proposed biological equivalent exposure limit: $80 \mu \mathrm{g} \cdot \mathrm{I}^{-1}(16)$.

b Biological exposure index of the American Conference of Governmental Industrial Hygienists: $800 \mathrm{mg} \cdot \mathrm{g}$ creatinin $^{-1}(5)$.
Case 2. PL, a 46-year-old man, had an unremarkable past medical history, was not taking medication, and was not at risk of HIV infection. He had been smoking 15 cigarettes per day for the last 27 years. Daily alcohol intake did not exceed $36 \mathrm{~g}$ of pure ethanol. There was no history of drug abuse. From 1987 to 1992 he had been exposed to styrene in hand lamination of fiber-glass reinforced products.

The biological monitoring results obtained in 1991 and 1992 are reported in table 1. From the spring of 1991, he reported leg weakness, thigh cramps, and "glove" paresthesias (tingling and numbness), especially at night. His physical and neurological examinations were unrevealing. As in the previous case, the laboratory tests were normal, as was the chest X-ray.

EMG showed, as in the co-worker, a moderate sensorimotor neuropathy of a demyelinating type. The right peroneal MCV was reduced $\left(42 \mathrm{~m} \cdot \mathrm{s}^{-1}\right)$, the distal and proximal latencies were increased ( 5 and $15 \mathrm{~ms}$, respectively), and the MAP had a polyphasic shape. The SCV value of the right sural and median nerves was also reduced (42 and $37 \mathrm{~m} \cdot \mathrm{s}^{-1}$, respectively). The sural SAP had a low amplitude $(4 \mu \mathrm{V})$. Fibrillation and fasciculation were not revealed by the EMG. Compared with our reference values, the $\mathrm{D}-15 \mathrm{~d}$ test results suggested a subclinical impairment of color vision: the CCI was 2.10, while the 10th and 90th percentiles determined for a group of 61 unexposed subjects over 40 years of age were 1.007 and 1.32, respectively. As for the other worker, a new electrophysiological examination was performed one year later; it confirmed decreased MCV of the right peroneal, median, and ulnar nerves $\left(43 \mathrm{~m} \cdot \mathrm{s}^{-1}\right.$, $49 \mathrm{~m} \cdot \mathrm{s}^{-1}$ and $45 \mathrm{~m} \cdot \mathrm{s}^{-1}$, respectively), whereas the MAP amplitude, DL, and PL were in the normal range. The left ulnar SCV was reduced $\left(47 \mathrm{~m} \cdot \mathrm{s}^{-1}\right)$. His color vision was slightly improved, but still abnormal $(\mathrm{CCI}=1.59)$.

\section{Discussion}

On the whole, the symptoms reported by the two workers and the electrophysiological results (decrease in MCV and SCV, increased latencies, normal MAP amplitude and absence of denervation) are consistent with demyelinating neuropathy. The symptoms, above all numbness of the upper extremities and weakness in the distal muscles of the lower extremities, are typical of peripheral neuropathies induced by medium- or long-term exposure to solvents (12).

Our electrophysiological data agree with those previously reported for styrene-exposed workers, and they indicate a decrease in motor $(6,8)$ and sensory (7) nerve conduction velocities. An impairment of the faster myelinated fibers of the peripheral nervous system in workers exposed to the solvents was reported by Murata et al (9). Other studies have also reported a decrease, although 
not significant, in sensory conduction velocity after styrene exposure $(10,13)$.

The histological findings of Behari et al (8) disclosed myelin degeneration in sural nerve bioptic samples from a worker exposed to presumably high environmental levels of styrene.

From 1991 to 1992, the styrene exposure of the workers in our study remained substantially unchanged (table 1). In a new examination, performed one year after the first, the electrophysiological results were similar, and therefore indicated a chronic course of peripheral neuropathy.

The only other solvent used in the workplace of our study was acetone; its use was occasional, limited to a few minutes a day, to clean the tools when needed. In a previous study in a similar workplace (14) environmental airborne levels of acetone were always low, never exceeding $500 \mathrm{mg} \cdot \mathrm{m}^{-3}$ in several spot samples collected during different moments of the workday, including tool cleaning. No other neurotoxic chemicals were present. The use of vibrating hand tools was excluded for both workers.

For both workers principal inherited causes of polyneuropathy were excluded by personal history. Polyneuropathies related to alcohol and drug abuse were ruled out by the workers' unremarkable personal history and laboratory tests. Neuropathies due to disvitaminosis, paraproteinemias, diabetes, and hepatic and renal diseases were excluded by laboratory tests. Neither case had a history of risk factors for HIV infection; the absence of clinical infectious diseases was confirmed in the examination in 1992. Paraneoplastic neuropathy was ruled out by personal history, laboratory data, and a normal chest $\mathrm{X}$-ray, and the results were confirmed in the follow-up examination performed in 1992. As a consequence, occupational exposure to styrene seems the most likely cause of the clinical peripheral neuropathy observed in the examined workers.

The mechanism of styrene peripheral neurotoxicity is still unknown. Some authors suggest a primary myelinotoxic action since, like other solvents, styrene can bind to membrane proteins and cause neuronal damage by interfering with the properties of membrane integral enzymes (15). Alternatively, styrene neurotoxicity may be due to its metabolite styrene epoxide, which can deplete glutathione and cause lipid peroxidation (1). Nevertheless, alternative mechanisms can be assumed, and the exact pathogenesis needs to be elucidated.

A subclinical impairment of color vision, involving blue-yellow discrimination, was present in both of the workers in our study; this result further indicates that styrene exposure can induce neurotoxic effects on the visual system (11). The pathogenesis of styrene-induced loss of color vision is not clear, but it may represent an early effect of toxic demyelination of the optic fibers, as postulated for other solvents (16). According to this hypothesis, all the findings observed for the two workers can be explained as consequences of a similar pathogenetic mechanism induced by styrene on the myelin sheath.

As indicated by the results of the biological monitoring, the occupational exposure of one of the two workers (PL) was about 20-50\% higher than the biological limits adopted for styrene in the United States $(5,14)$. The values obtained for the other worker (CC) were closer to the limit, but the symptoms appeared at the end of a period of increased production of fiber-glass reinforced plastics products, and therefore possibly resulted in increased exposure. As a consequence, in the period preceding the appearance of clinical symptoms, the exposure of $\mathrm{CC}$ was probably of in the same order as that measured for PL.

The two subjects were from a group of 20 fiber-glass reinforced plastics workers in a small factory. The results of the biological monitoring previously performed for the other laminators were similar to those observed for CC and PL; they suggest a substantially stable exposure over time. No other cases of clinical peripheral sensorimotor neuropathy were observed.

In Europe, exposures ranging between $100 \%$ and $150 \%$ of the TLV-TWA proposed by the ACGIH are common during the production of glass-reinforced plastics products (17).

In two previous papers reporting peripheral neuropathies in styrene workers, the exposure levels were not evaluated, but they were presumably high $(6,8)$. In another study, mild sensory nerve conduction deficits, but not clinical symptoms, were observed in $23 \%$ and $71 \%$ of the workers exposed to environmental styrene levels exceeding 50 and $100 \mathrm{ppm}$, respectively (7). A significant reduction in the conduction velocities of the sensory motor nerve has been suggested for workers exposed to mean environmental levels of styrene corresponding to about $50 \%$ of the current ACGIH TLV-TWA; notably, no clinical symptoms or signs of peripheral neuropathy were reported for these workers (9). Furthermore, other authors have failed to observe significant clinical or electrophysiological signs of peripheral neuropathy in groups of workers exposed to various levels of styrene $(1,10)$.

Some recently published papers, including data on styrene-induced loss of color vision (11), support the hypothesis that the current limit proposed for styrene by the ACGIH is not protective enough, at least considering the effects of the solvent on the nervous system $(1-4$, 11). As a consequence, countries like Germany, Sweden, and Finland drastically reduced their occupational exposure limits (18).

To our knowledge, these are the first overt clinical peripheral neuropathies reported for fiber-glass reinforced plastics workers exposed to environmental levels 
of styrene ranging around the ACGIH limits, or slightly higher. The occurrence of two cases in the same occupational group of workers, the absence of a relevant exposure to other neurotoxic chemicals, the concomitant presence of a subclinical impairment of color vision in both workers, and the possible common pathogenetic mechanism support the hypothesis that all the observed symptoms and signs were due to styrene neurotoxicity.

The results further raise the question of the real preventive meaning of the ACGIH limit of $50 \mathrm{ppm}$, at least on the individual basis. The need to reconsider the current limit must be evaluated.

\section{References}

1. Pahwa R, Kalra J. A critical review of the neurotoxicity of styrene in humans. Vet Hum Toxicol 1993;35:516-20

2. Jegaden D, Amann D, Simon JF, Habault H, Legonx B, Galopin P. Study of the neurobehavioural toxicity of styrene at low levels of exposure. Int Arch Occup Environ Health 1993;64: $527-31$.

3. Härkönen H, Lindström K, Seppäläinen AM, Asp S, Hernberg S. Exposure-response relationship between styrene exposure and central nervous functions. Scand J Work Environ Health 1978;4:53-9.

4. Mutti A, Mazzucchi A, Rustichelli P, Frigeri G, Arfini G, Franchini I. Exposure-effect and exposure-response relationships between occupational exposure to styrene and neuropsychological functions. Am J Ind Med 1984;5:275-80.

5. American Conference of Industrial Governmental Hygienists (ACGIH). Threshold limit values for chemical substances and physical agents and biological exposure indices for 1993-94. Cincinnati OH: ACGIH, 1993.

6. Lilis R, Lorimer WV, Diamond S, Selikoff IJ. Neurotoxicity of styrene in production and polymerization workers. Environ Res 1978;15:133-8.

7. Cherry N, Gautrin D. Neurotoxic effects of styrene: further evidence. Br J Ind Med 1990;47:29—37.

8. Behari M, Choudhary C, Roy S, Maheshwari MC. Styrene- induced peripheral neuropathy: a case report. Eur Neurol 1986 25:424-7

9. Murata K, Araki S, Yokoyama K. Assessment of the peripheral, central and autonomic nervous system function in styrene workers. Am J Ind Med 1991;20:775-84.

10. Triebig G, Shaller $\mathrm{K}-\mathrm{H}$, Valentin $\mathrm{H}$. Investigations on neurotoxicity of chemical substances at the workplace: VII. Longitudinal study with determination of nerve conduction velocities in persons occupationally exposed to styrene. Int Arch Occup Environ Health 1985;56:239 47

11. Gobba F, Galassi C, Imbriani M, Ghittori S, Candela S, Cavalleri A. Acquired dyschromatopsia among styrene-exposed workers. J Occup Med 1991;33:761—5.

12. Johnson BJ, editor. Prevention of neurotoxic illness in working populations. Chichester: John Wiley \& Sons, 1987.

13. Rosén I, Haeger-Aronsen B, Rehnström S, Welinder H. Neurophysiological observations after chronic styrene exposure. Scand J Work Environ Health 1978;4 suppl 2:184-94.

14. Gobba F, Galassi C, Ghittori S, Imbriani M, Pugliese F, Cavalleri A. Urinary styrene in the biological monitoring of styrene exposure. Scand J Work Environ Health 1993;19:175-82.

15. Tahti $\mathrm{H}$. The neurotoxicity of organic solvents, studied with in vitro models. Alternatives Lab Anim 1992;20:290—6.

16. Schaumburg HH, Spencer PS. Environmental hydrocarbons produce degeneration in cat hypothalamus and optic tract. Science 1978;199:199-200.

17. Pfäffli P, Säämänen A. The occupational scene of styrene. In: Sorsa M, Peltonen K, Vainio H, Hemminki K, editors. Butadiene and styrene: assessment of health hazards. Lyon: International Agency for Research on Cancer (IARC), 1993:15-26. IARC scientific publications, no 127.

18. Matikainen E, Forsman-Grönholm L, Pfäffli P, Juntunen J. Neurotoxicity in workers exposed to styrene. In: Sorsa $\mathrm{M}$, Peltonen K, Vainio H, Hemminki K, editors. Butadiene and styrene: assessment of health hazards. Lyon: International Agency for Research on Cancer (IARC), 1993:153-61. IARC scientific publications, no 127.

Received for publication: 27 June 1995 